\title{
Analysis of aroma-active compounds in three sweet osmanthus (Osmanthus fragrans) cultivars by GC-olfactometry and GC-MS*
}

\author{
Xuan $\mathrm{CAI}^{1}$, Rong-zhang MAI ${ }^{1,2}$, Jing-jing ZOU ${ }^{1}$, Hong-yan $\mathrm{ZHANG}^{1}$, \\ Xiang-ling ZENG ${ }^{1}$, Ri-ru ZHENG ${ }^{1}$, Cai-yun $\mathrm{WANG}^{\dagger+1}$ \\ $\left({ }^{1}\right.$ Key Laboratory of Horticultural Plant Biology, Ministry of Education, Huazhong Agricultural University, Wuhan 430070, China) \\ $\left({ }^{2}\right.$ Guangxi Communications Investment Group Yulin Expressway Operation Co., Ltd., Yulin 537000, China) \\ †E-mail: wangcy@mail.hzau.edu.cn \\ Received Feb. 27, 2014; Revision accepted May 7, 2014; Crosschecked June 20, 2014
}

\begin{abstract}
Objective: Aroma is the core factor in aromatherapy. Sensory evaluation of aromas differed among three sweet osmanthus (Osmanthus fragrans) cultivar groups. The purpose of this study was to investigate the aroma-active compounds responsible for these differences. Methods: Gas chromatography-olfactometry (GC-O) and GC-mass spectrometry (GC-MS) were used to analyze the aroma-active compounds and volatiles of creamy-white ('Houban Yingui', HBYG), yellow ('Liuye Jingui', LYJG), and orange ('Gecheng Dangui', GCDG) cultivars. Results: Seventeen aroma-active compounds were detected among 54 volatiles. trans- $\beta$-Ocimene, trans- $\beta$-ionone, and linalool, which were major volatiles, were identified as aroma-active, while cis-3-hexenyl butanoate, $\gamma$-terpinene, and hexyl butanoate were also aroma-active compounds, although their contents were low. Analysis of the odors was based on the sum of the modified frequency (MF) values of aroma-active compounds in different odor groups. HBYG contained more herb odors, contributed by cis- $\beta$-ocimene and trans- $\beta$-ocimene, while LYJG had more woody/violet/fruity odors released by trans- $\beta$-ionone, $\alpha$-ionone, and hexyl butanoate. In GCDG, the more floral odors were the result of cis-linalool oxide, trans-linalool oxide, and linalool. Conclusions: Aroma-active compounds were not necessarily only the major volatiles: some volatiles with low content also contributed to aroma. The aroma differences among the three cultivars resulted from variation in the content of different odor groups and in the intensities of aroma-active compounds.
\end{abstract}

Key words: Gas chromatography-olfactometry (GC-O), Gas chromatography-mass spectrometry (GC-MS), Aroma, Sweet osmanthus (Osmanthus fragrans)

doi: $10.1631 /$ jzus.B1400058

Document code: A

CLC number: S68

\section{Introduction}

Sweet osmanthus (Osmanthus fragrans) is an important ornamental plant of the family Oleaceae (Yuan et al., 2011). It is widely distributed in China, Japan, Thailand, and India, and was introduced in Europe late in the 18th century (Zang et al., 2003). Owing to their pleasant scent and biological proper-

\footnotetext{
\$Corresponding author

* Project supported by the PhD Program Foundation of the Ministry of Education of China (No. 20130146110022) and the National Natural Science Foundation of China (No. 31070623)

(C) Zhejiang University and Springer-Verlag Berlin Heidelberg 2014
}

ties, sweet osmanthus flowers are not only used as natural and functional food flavor additives (Wu et al., 2009), but also have potential medicinal value (Tsai et al., 2007; Lee et al., 2011; Hung et al., 2012). The sensory perception of the aromas in the Albus (former $O$. fragrans var. latifolius), Luteus (former $O$. fragrans var. thunbergii), and Aurantiacus (former $O$. fragrans var. aurantiacus) groups has been described as variable (Hu et al., 2012). Since aroma is the core factor in aromatherapy applications (Buchbauer et al., 1993), understanding the differences among sweet osmanthus cultivars has become one of the primary goals to improve the value of sweet osmanthus in commercial aromatherapy applications. 
Volatiles have been determined by gas chromatography-mass spectrometry (GC-MS) to reveal the aroma differences among sweet osmanthus cultivar groups, but different extraction methods might affect volatile composition (Zhu et al., 1985; Wang et al., 2009; Hu et al., 2012). Solid-phase microextraction (SPME), a simple, rapid, sensitive, and solvent-free technique for flower aroma analysis, is considered largely to retain the natural aroma (Montero-Calderón et al., 2010). Using SPME, Xin et al. (2013) found a high degree of similarity in aroma characteristics within the same cultivar group, and that the high relative contents of cis- and trans-linalool oxide (furan), trans-2-hexenal, and cis-3-hexen-1-ol might affect the aromas of sweet osmanthus. Cao et al. (2009) suggested that the different relative contents of linalool, $\alpha$-ionone, $\beta$-ionone, ocimene, and $\gamma$-decalactone in Albus, Luteus, and Aurantiacus cultivar groups led to variable aromas. However, the odor contributions of these volatile compounds in sweet osmanthus were not clear.

GC-MS is useful for qualitative and quantitative analyses of aroma profiles, but it does not provide an accurate indication of aroma as it does not record odor perceptions (Miyazaki et al., 2012). GC-olfactometry (GC-O) is an essential tool to study the contribution of aroma-active compounds (van Ruth, 2001), simultaneously detecting volatiles and using human assessors to sniff and describe their odors (Sides et al., 2000). It has been widely used to identify aromaactive compounds in many species such as Crocus sativus (Culleré et al., 2011), Laurus nobilis (Kilic et al., 2004), and Chrysanthemum coronarium (Zheng et al., 2004). However, to our knowledge, there is no report comparing aroma-active compounds of different sweet osmanthus cultivars by GC-O.

Here we investigated the volatiles and aromaactive compounds of three sweet osmanthus cultivars, which have high economic value in the central region of China (Zhou et al., 2006). The semi-quantified results obtained by GC-MS and the aroma contributions analyzed by GC-O will provide useful information for the application of different sweet osmanthus cultivars in biomedical science, and will be helpful for further biotechnological research on the aroma of sweet osmanthus.

\section{Materials and methods}

\subsection{Plant materials}

Fresh flowers of three sweet osmanthus cultivars, at full flowering stage, were harvested in the nursery of Huazhong Agricultural University (Wuhan, China) in September 2012, between 7 a.m. and 9 a.m. The orange-flowered 'Gecheng Dangui' (GCDG) is from the Aurantiacus group, 'Houban Yingui' (HBYG), with creamy-white flowers, is from the Albus group, and 'Liuye Jingui' (LYJG), with yellow flowers, is a member of the Luteus group (Fig. 1). Collected flowers within each cultivar were mixed well and divided into $2 \mathrm{~g}$ samples. All samples were immediately put into airtight polyethylene bags, frozen and stored at $-20^{\circ} \mathrm{C}$ prior to analysis (Xin et al., 2013). Three biological replicates of each cultivar were used in each experiment.

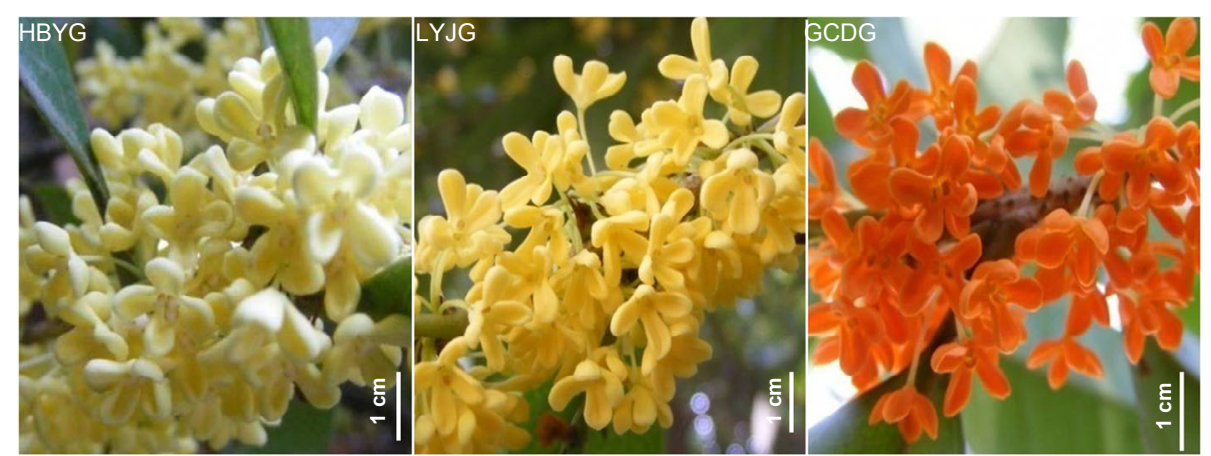

Fig. 1 Flowers of the three sweet osmanthus (Osmanthus fragrans) cultivars

'Houban Yingui' (HBYG) is a cultivar in the Albus group with creamy-white flowers; 'Liuye Jingui' (LYJG) is a cultivar of the Luteus group with yellow flowers; 'Gecheng Dangui' (GCDG) is a cultivar of the Aurantiacus group with orange flowers (Note: for interpretation of the references to color in this figure legend, the reader is referred to the web version of this article) 


\subsection{Standards and solvents}

The $n$-alkane standards $\left(\mathrm{C}_{8}-\mathrm{C}_{20}\right)$, methyl laurate as internal standard, and the referenced authentic standards including trans-3-hexenol, $\beta$-myrcene, 4-hexen-1-ol, acetate, 3-carene, limonene, cis- $\beta$ ocimene, trans- $\beta$-ocimene, $\gamma$-terpinene, cis-linalool oxide, trans-linalool oxide, allo-ocimene, cis-3hexenyl iso-butyrate, cis-3-hexenyl butanoate, hexyl butanoate, cis-3-hexenyl-2-methylbutanoate, cisgeraniol, linalyl formate, citral, cis-3-hexenyl hexanoate, $\quad c i s$-jasmone, $\alpha$-ionone, dihydro- $\beta$-ionone, geranyl acetone, $\gamma$-decalactone, and trans- $\beta$-ionone, were obtained from Sigma Co., Ltd. (St. Louis, MO, USA). Naphthalene, 2-methylnaphthalene, butylated hydroxytoluene, cis-3-hexenyl acetate, D-limonene, and linalool were obtained from Alfa Aesar Co., Ltd. (Heysham, Lancashire, UK).

\subsection{SPME extraction}

SPME fibers (50/30 $\mu \mathrm{m}$ divinylbenzene/carboxen/ polydimethylsiloxane (DVB/CAR/PDMS) on a 2-cm StableFlex fiber, Supelco Bellefonte, PA, USA) were used to collect and concentrate the aroma compounds. Before the samples were loaded, the fiber was inserted into a $\mathrm{GC}$ injector $\left(250^{\circ} \mathrm{C}\right)$ and held for $1 \mathrm{~h}$, according to the manufacturer's instructions. Each flower sample (2 g) was put in a 20 -ml glass vial, capped securely with an aluminum seal and a Teflon septum, with $1-\mu l$ methyl laurate $(0.87 \mathrm{mg} / \mathrm{ml}$ in methanol) added as the internal standard (the final concentration of internal standard in each sample was $0.435 \mu \mathrm{g} / \mathrm{g}$ ). After a 30 -min equilibration period at room temperature $\left[(25 \pm 2){ }^{\circ} \mathrm{C}\right]$, the fiber was inserted into the capped vial for absorption (15 $\mathrm{min})$.

\subsection{GC-MS analysis}

The system was a TRACE GC Ultra GC coupled to a DSQ II mass spectrometer (Thermo Fisher Scientific, Waltham, MA, USA). The GC was fitted with an HP-5 column $(30 \mathrm{~m} \times 0.25 \mathrm{~mm} \times 0.25 \mu \mathrm{m}$, Thermo Scientific, Bellefonte, PA, USA). The GC-MS conditions were modified from Xin et al. (2013). The injector was maintained at $250{ }^{\circ} \mathrm{C}$, with a transfer line temperature of $280{ }^{\circ} \mathrm{C}$. The ion energy of electron impact ionization was $70 \mathrm{eV}$ and the scanning range was 40-450 Da, with the ion source temperature set to $230{ }^{\circ} \mathrm{C}$. The flow rate of the helium (99.999\%) carrier gas was $1.2 \mathrm{ml} / \mathrm{min}$. Analytes absorbed on the fiber were desorbed for $3 \mathrm{~min}$ in the GC injector at $250{ }^{\circ} \mathrm{C}$ in splitless mode. The temperature isothermal was set at $40{ }^{\circ} \mathrm{C}$ for $3 \mathrm{~min}$, and then increased from $40{ }^{\circ} \mathrm{C}$ to $73{ }^{\circ} \mathrm{C}$ at $3{ }^{\circ} \mathrm{C} / \mathrm{min}$, held at $73{ }^{\circ} \mathrm{C}$ for $3 \mathrm{~min}$, and finally raised to $220^{\circ} \mathrm{C}$ at the rate of $5{ }^{\circ} \mathrm{C} / \mathrm{min}$, and held for $1 \mathrm{~min}$.

\subsection{GC-O analysis}

GC-O analysis was carried out using an HP 6890 GC coupled with an Agilent 5975 Network mass spectrometer (Agilent Technologies, Palo Alto, CA, USA) and equipped with a sniffing port (ODP2, Gerstel Inc., Baltimore, MD, USA). The helium carrier gas flow was set at a constant rate of $1 \mathrm{ml} / \mathrm{min}$. Samples were analyzed on an HP-5 column (30 m× $0.25 \mathrm{~mm} \times 0.25 \mu \mathrm{m}, \mathrm{J} \& \mathrm{~W}$ Scientific, Folsom, CA, USA). Analytes absorbed on the SPME fiber were desorbed for $3 \mathrm{~min}$ in the $\mathrm{GC}$ injector at $250{ }^{\circ} \mathrm{C}$. The GC effluent was split 1:1 between the MS and the sniffing port (Kang et al., 2012). The injector and detector were maintained at $250{ }^{\circ} \mathrm{C}$. The temperature program was modified according to Xin et al. (2013) and set to $40^{\circ} \mathrm{C}$ for $3 \mathrm{~min}$, and then increased from 40 to $73{ }^{\circ} \mathrm{C}$ at $3{ }^{\circ} \mathrm{C} / \mathrm{min}$, held at $73{ }^{\circ} \mathrm{C}$ for $3 \mathrm{~min}$, and finally raised to $220{ }^{\circ} \mathrm{C}$ at the rate of $5{ }^{\circ} \mathrm{C} / \mathrm{min}$ and held for $1 \mathrm{~min}$.

In this GC-O study, assessments were carried out by a panel of three expert judges. Each sample was smelled twice by each panelist. Panelists were asked to evaluate the overall intensity of each perceived odor using a 5-point scale ( 0 , not detected; 1 , extremely weak; 2 , clear and medium intense; 3 , intense; 4 , extremely strong). The olfactometric strategy used in this study was combined with measurements of intensity and frequency of detection. This method has been proven in many studies to be the least time-consuming and the easiest handling method to provide reliable results (Culleré et al., 2011; Ubeda et al., 2012). The parameter known as 'modified frequency' (MF, \%) was calculated using the formula proposed by Dravnieks (1985): $\mathrm{MF}=(F I)^{1 / 2}$, where $F$ $(\%)$ is the detection frequency of an aromatic attribute expressed as the percentage of the total number of judges and $I(\%)$ is the average intensity expressed as the percentage of the maximum intensity. 


\subsection{Component identification}

Identification of the aroma-active and volatile compounds was based on a comparison of their olfactory descriptions, mass spectra, and retention indices (RIs) with the authentic standards and published data, as well as standard mass spectra in the NIST05. RI values were calculated using a homologous series of $n$-alkane standards on HP-5 columns. Methyl laurate was used as an internal standard for semi-quantification analysis. By comparing the GC-peak area of each volatile compound with that of the internal standard, relative units were used to express the contents of the volatiles (Kaseleht et al., 2011).

\subsection{Statistical analysis}

The data were expressed as mean \pm standard deviation (SD) of triplicate measurements. One-way analysis of variance (ANOVA) with Tukey's test in SAS software was used to assess differences in aroma compounds among the three sweet osmanthus cultivars.

\section{Results}

\subsection{Volatiles analyzed by GC-MS}

The volatiles of the three cultivars are given in Table 1, with the components listed in order of their RI on the HP-5 column. A total of 41, 48, and 51 volatiles were detected in HBYG, LYJG, and GCDG respectively.

Based on Knudsen et al. (2006)'s classification of aroma compounds, the volatiles of sweet osmanthus were assigned to terpenoid compounds, fatty acid-derived/other lipophilic flavor compounds, phenylpropanoid/benzenoid compounds, or nitrogencontaining flavor compounds. Terpenoid compounds predominated, while other compounds were typically present in smaller amounts.

The contents of volatile compounds varied markedly among the three cultivars. In HBYG, trans- $\beta$-ocimene (403.22 relative units) was most abundant, and its content was 9.11-fold higher than that of the yellow LYJG and 2.26-fold higher than that of the orange GCDG. trans- $\beta$-Ionone $(91.35$ relative units), linalool (85.75 relative units), and dihydro- $\beta$-ionone (34.66 relative units) were also major volatiles in HBYG. In LYJG, the content of the volatile compound trans- $\beta$-ionone (388.19 relative units) was the highest, 4.30-fold higher than in HBYG and 12.33-fold higher than in GCDG. Other predominant components in LYJG were linalool (178.79 relative units), $\gamma$-decalactone (57.30 relative units), and trans- $\beta$-ocimene (44.25 relative units). In GCDG, the content of linalool was 308.68 relative units, which was 3.60-fold higher than that in HBYG and 1.73-fold higher than that in LYJG. GCDG was also characterized by a high content of trans- $\beta$-ocimene (190.62 relative units), trans-linalool oxide (70.79 relative units), cis-linalool oxide (42.89 relative units), $\beta$-myrcene (34.02 relative units), and trans- $\beta$-ionone (31.49 relative units).

\subsection{Aroma-active compounds analyzed by GC-O}

GC-O was used to investigate the aroma-active compounds of the three sweet osmanthus cultivars. The results are shown in Table 2, with the RI, odorant descriptors, and odor intensities given as MF (\%).

A total of 17 aroma-active compounds were detected in the three cultivars. Among these compounds, D-limonene, cis- $\beta$-ocimene, trans- $\beta$-ocimene, cis-linalool oxide, trans-linalool oxide, linalool, allo-ocimene, neo-allo-ocimene, cis-linalol oxide (pyranoid), $\alpha$-ionone, trans- $\beta$-ionone, cis-3-hexenyl butanoate, and hexyl butanoate were common in the three cultivars. Some aroma-active compounds were present only in single cultivars: hotrienol and 1,2-dihydro-1,5,8-trimethylnaphthalene were detected only in LYJG, while $\gamma$-terpinene and 6-ethenyldihydro-2,2,6-trimethyl$2 \mathrm{H}$-pyran-3(4H)-one were considered to contribute to the aroma of HBYG and GCDG.

trans- $\beta$-Ionone, giving violet/woody odors, was the major aroma-active compound of LYJG. Its MF value was $98 \%$, much higher than those of HBYG and GCDG. Similar odors were contributed by $\alpha$-ionone, with MF values of $59 \%$ in LYJG, $42 \%$ in $\mathrm{HBYG}$, and $17 \%$ in GCDG. Note that the MF value of trans- $\beta$ ocimene reached $96 \%$ in $\mathrm{HBYG}$, significantly higher than that in LYJG and GCDG. Linalool, with a typical floral odor, was perceived as the most important aroma-active compound, with the highest MF value (98\%) in GCDG. Linalool-derived compounds, including cis-linalool oxide, trans-linalool oxide, and cis-linalool oxide (pyranoid), were identified as aroma-active compounds giving the green and citrus notes accompanied by floral and sweet notes in sweet osmanthus. 
Table 1 Volatile compounds in flowers of the three sweet osmanthus (Osmanthus fragrans) cultivars

\begin{tabular}{|c|c|c|c|c|c|}
\hline \multirow{2}{*}{ RI } & \multirow{2}{*}{ Compound } & \multicolumn{3}{|c|}{ Content relative to internal standard (relative unit) } & \multirow{2}{*}{ ID } \\
\hline & & HBYG & LYJG & GCDG & \\
\hline 732 & 4-[2-(Methylamino)ethyl]-1,2-benzenediol & $0.23 \pm 0.13 b$ & $1.65 \pm 0.26 \mathrm{~b}$ & $5.34 \pm 1.44 \mathrm{a}$ & $\mathrm{M}$ \\
\hline 753 & $\begin{array}{l}\text { Hydroxy[(1-oxo-2-propenyl)amino]-acetic } \\
\text { acid }\end{array}$ & $0.41 \pm 0.22 b$ & $0.93 \pm 0.13 b$ & $2.03 \pm 0.70 \mathrm{a}$ & M \\
\hline 869 & trans-3-Hexenol & $0.26 \pm 0.09 b$ & $0.93 \pm 0.41 \mathrm{a}$ & $1.39 \pm 0.26 \mathrm{a}$ & $\mathrm{M}, \mathrm{R}, \mathrm{C}$ \\
\hline 998 & $\beta$-Myrcene & $7.80 \pm 3.66 \mathrm{~b}$ & $17.81 \pm 14.21 \mathrm{ab}$ & $34.02 \pm 2.91 \mathrm{a}$ & M, R, C \\
\hline 1009 & 4-Hexen-1-ol, acetate & $5.34 \pm 1.06$ & nd & nd & $\mathrm{M}, \mathrm{R}, \mathrm{C}$ \\
\hline 1012 & cis-3-Hexenyl acetate & $0.67 \pm 0.48 b$ & $23.95 \pm 9.55 \mathrm{a}$ & $11.63 \pm 0.95 b$ & $\mathrm{M}, \mathrm{R}, \mathrm{C}$ \\
\hline 1018 & 3-Carene & $0.46 \pm 0.35 \mathrm{a}$ & nd & $0.35 \pm 0.15 \mathrm{ab}$ & $\mathrm{M}, \mathrm{R}, \mathrm{C}$ \\
\hline 1030 & D-Limonene & $5.22 \pm 1.68 b$ & $7.66 \pm 6.43 b$ & $18.10 \pm 3.13 \mathrm{a}$ & $\mathrm{M}, \mathrm{R}, \mathrm{C}$ \\
\hline 1036 & Limonene & $0.17 \pm 0.09 \mathrm{ab}$ & $0.12 \pm 0.05 b$ & $0.38 \pm 0.18 \mathrm{a}$ & $\mathrm{M}, \mathrm{R}, \mathrm{C}$ \\
\hline 1041 & cis- $\beta$-Ocimene & $15.75 \pm 3.63 \mathrm{a}$ & $4.26 \pm 0.26 b$ & $11.60 \pm 2.68 \mathrm{a}$ & M, R, C \\
\hline 1051 & trans- $\beta$-Ocimene & $403.22 \pm 131.13 \mathrm{a}$ & $44.25 \pm 23.78 b$ & $190.62 \pm 27.19 b$ & $\mathrm{M}, \mathrm{R}, \mathrm{C}$ \\
\hline 1061 & $\gamma$-Terpinene & $1.60 \pm 0.10 \mathrm{a}$ & $0.61 \pm 0.31 \mathrm{~b}$ & $1.33 \pm 0.39 \mathrm{a}$ & $\mathrm{M}, \mathrm{R}, \mathrm{C}$ \\
\hline 1075 & cis-Linalool oxide & $18.50 \pm 2.67 b$ & $10.27 \pm 9.61 \mathrm{~b}$ & $42.89 \pm 0.80 \mathrm{a}$ & $\mathrm{M}, \mathrm{R}, \mathrm{C}$ \\
\hline 1085 & Isoterpinolene & $0.78 \pm 0.35 \mathrm{a}$ & nd & $0.20 \pm 0.13 b$ & M, R \\
\hline 1091 & trans-Linalool oxide & $17.84 \pm 4.23 b$ & $10.67 \pm 8.98 b$ & $70.79 \pm 0.91 \mathrm{a}$ & $\mathrm{M}, \mathrm{R}, \mathrm{C}$ \\
\hline 1103 & Linalool & $85.75 \pm 3.86 b$ & $178.79 \pm 90.03 b$ & $308.68 \pm 65.96 a$ & $\mathrm{M}, \mathrm{R}, \mathrm{C}$ \\
\hline 1106 & Hotrienol & nd & $0.38 \pm 0.22 \mathrm{ab}$ & $1.04 \pm 0.71 \mathrm{a}$ & $\mathrm{M}, \mathrm{R}$ \\
\hline 1110 & $\begin{array}{l}\text { 6-Ethenyldihydro-2,2,6-trimethyl-2H- } \\
\text { pyran-3(4H)-one }\end{array}$ & $2.20 \pm 1.07 \mathrm{a}$ & nd & $2.58 \pm 0.27 \mathrm{a}$ & M, R \\
\hline 1121 & $\begin{array}{l}\text { 2-Ethenyl-1,1-dimethyl-3- } \\
\text { methylenecyclohexane }\end{array}$ & $0.09 \pm 0.00 \mathrm{ab}$ & nd & $0.23 \pm 0.13 \mathrm{a}$ & M \\
\hline 1126 & 2,6-Dimethyl-1,3(E),5(E),7-octatetraene & $2.00 \pm 0.09 \mathrm{a}$ & $0.26 \pm 0.09 b$ & $0.32 \pm 0.13 b$ & M, R \\
\hline 1133 & Allo-ocimene & $20.24 \pm 3.40 \mathrm{a}$ & $3.80 \pm 0.33 \mathrm{c}$ & $13.02 \pm 0.75 b$ & $\mathrm{M}, \mathrm{R}, \mathrm{C}$ \\
\hline 1146 & Neo-allo-ocimene & $12.38 \pm 2.90 \mathrm{a}$ & $1.68 \pm 0.41 \mathrm{c}$ & $6.41 \pm 0.36 b$ & M, R \\
\hline 1150 & cis-3-Hexenyl iso-butyrate & nd & $1.07 \pm 0.13 \mathrm{a}$ & $0.12 \pm 0.05 b$ & $\mathrm{M}, \mathrm{R}, \mathrm{C}$ \\
\hline 1172 & Epoxylinalol & $3.92 \pm 0.46 \mathrm{a}$ & $1.16 \pm 0.35 b$ & $5.57 \pm 1.85 \mathrm{a}$ & M, R \\
\hline 1178 & cis-Linalool oxide (pyranoid) & $5.63 \pm 2.50 \mathrm{~b}$ & $4.15 \pm 4.40 \mathrm{~b}$ & $14.33 \pm 4.29 \mathrm{a}$ & $\mathrm{M}, \mathrm{R}$ \\
\hline 1180 & Naphthalene & nd & $0.29 \pm 0.18$ & nd & $\mathrm{M}, \mathrm{R}, \mathrm{C}$ \\
\hline 1191 & cis-3-Hexenyl butanoate & $0.99 \pm 0.22 b$ & $20.82 \pm 9.15 \mathrm{a}$ & $3.05 \pm 0.97 b$ & $\mathrm{M}, \mathrm{R}, \mathrm{C}$ \\
\hline 1197 & Hexyl butanoate & $0.23 \pm 0.13 b$ & $1.22 \pm 0.23 \mathrm{a}$ & $0.17 \pm 0.09 b$ & $\mathrm{M}, \mathrm{R}, \mathrm{C}$ \\
\hline 1233 & cis-Geraniol & nd & nd & $0.26 \pm 0.09$ & $\mathrm{M}, \mathrm{R}, \mathrm{C}$ \\
\hline 1237 & cis-3-Hexenyl-2-methylbutanoate & nd & $0.15 \pm 0.18 \mathrm{a}$ & $0.17 \pm 0.09 \mathrm{a}$ & $\mathrm{M}, \mathrm{R}, \mathrm{C}$ \\
\hline 1243 & cis-3-Hexenyl isovalerate & $0.26 \pm 0.09 b$ & $1.51 \pm 0.31 \mathrm{a}$ & $1.39 \pm 0.17 \mathrm{a}$ & $\mathrm{M}, \mathrm{R}$ \\
\hline 1260 & Linalyl formate & $0.15 \pm 0.10 \mathrm{ab}$ & $0.09 \pm 0.09 \mathrm{~b}$ & $0.38 \pm 0.18 \mathrm{a}$ & $\mathrm{M}, \mathrm{R}, \mathrm{C}$ \\
\hline 1267 & Megastigma-4,6(Z),8(Z)-triene & $0.12 \pm 0.05 \mathrm{a}$ & $0.15 \pm 0.13 \mathrm{a}$ & $0.32 \pm 0.10 \mathrm{a}$ & $\mathrm{M}, \mathrm{R}$ \\
\hline 1276 & Citral & nd & $0.06 \pm 0.05 b$ & $0.17 \pm 0.09 \mathrm{a}$ & $\mathrm{M}, \mathrm{R}, \mathrm{C}$ \\
\hline 1291 & 2-Methylnaphthalene & $0.17 \pm 0.15 b$ & $0.17 \pm 0.09 \mathrm{~b}$ & $0.44 \pm 0.09 \mathrm{a}$ & $\mathrm{M}, \mathrm{R}, \mathrm{C}$ \\
\hline 1332 & cis-Edulan & $8.44 \pm 3.96 \mathrm{a}$ & $6.50 \pm 2.14 \mathrm{a}$ & $0.26 \pm 0.09 b$ & $\mathrm{M}, \mathrm{R}$ \\
\hline 1343 & Megastigma-4,6(E),8(Z)-triene & $0.12 \pm 0.05 \mathrm{a}$ & $0.15 \pm 0.05 \mathrm{a}$ & $0.12 \pm 0.05 \mathrm{a}$ & $\mathrm{M}, \mathrm{R}$ \\
\hline 1354 & 1,2-Dihydro-1,5,8-trimethylnaphthalene & $0.90 \pm 0.22 b$ & $2.73 \pm 0.18 \mathrm{a}$ & $0.32 \pm 0.10 \mathrm{c}$ & $\mathrm{M}, \mathrm{R}$ \\
\hline 1358 & 1,1,4,5-Tetramethylindan & $1.39 \pm 1.23 \mathrm{ab}$ & $2.26 \pm 0.23 \mathrm{a}$ & $0.35 \pm 0.17 b$ & $\mathrm{M}, \mathrm{R}$ \\
\hline 1364 & Megastigma-4,6(E),8(E)-triene & $0.26 \pm 0.09 b$ & $0.90 \pm 0.44 \mathrm{a}$ & $0.35 \pm 0.09 b$ & $\mathrm{M}, \mathrm{R}$ \\
\hline 1369 & $\begin{array}{c}69(100), 41(40), 84(39), 94(30), 85(28) \\
109(20), 137(20), 67(18), 152(15), 123(10)\end{array}$ & $0.35 \pm 0.17 \mathrm{~b}$ & $0.99 \pm 0.22 \mathrm{a}$ & $0.32 \pm 0.18 b$ & \\
\hline 1372 & 1-Ethyl-3,5-diisopropylbenzene & $0.17 \pm 0.09 \mathrm{a}$ & $0.06 \pm 0.05 \mathrm{a}$ & $0.15 \pm 0.10 \mathrm{a}$ & M \\
\hline 1386 & cis-3-Hexenyl hexanoate & nd & $0.17 \pm 0.09 \mathrm{a}$ & $0.12 \pm 0.05 \mathrm{a}$ & $\mathrm{M}, \mathrm{R}, \mathrm{C}$ \\
\hline
\end{tabular}


Table 1

\begin{tabular}{|c|c|c|c|c|c|}
\hline \multirow{2}{*}{ RI } & \multirow{2}{*}{ Compound } & \multicolumn{3}{|c|}{ Content relative to internal standard (relative unit) } & \multirow{2}{*}{ ID } \\
\hline & & HBYG & LYJG & GCDG & \\
\hline 1401 & cis-Jasmone & $0.29 \pm 0.22 \mathrm{a}$ & $0.32 \pm 0.13 \mathrm{a}$ & $0.29 \pm 0.13 \mathrm{a}$ & $\mathrm{M}, \mathrm{R}, \mathrm{C}$ \\
\hline 1427 & $\beta$-Ionol & nd & $0.09 \pm 0.09$ & nd & M, R \\
\hline 1431 & $\alpha$-Ionone & $6.67 \pm 1.87 \mathrm{a}$ & $23.90 \pm 28.61 \mathrm{a}$ & $3.36 \pm 1.31 \mathrm{a}$ & $\mathrm{M}, \mathrm{R}, \mathrm{C}$ \\
\hline 1442 & Dihydro- $\beta$-ionone & $34.66 \pm 4.14 \mathrm{a}$ & $14.67 \pm 3.49 \mathrm{~b}$ & $6.38 \pm 1.38 \mathrm{c}$ & $\mathrm{M}, \mathrm{R}, \mathrm{C}$ \\
\hline 1459 & Geranyl acetone & nd & $0.15 \pm 0.10 \mathrm{a}$ & $0.12 \pm 0.05 \mathrm{ab}$ & $\mathrm{M}, \mathrm{R}, \mathrm{C}$ \\
\hline 1463 & $\begin{array}{c}141(100), 44(72), 115(45), 93(35), 69(33), \\
91(28), 67(25), 118(15), 105(14), 143(12)\end{array}$ & nd & $0.20 \pm 0.10 \mathrm{a}$ & $0.09 \pm 0.00 \mathrm{~b}$ & M \\
\hline 1471 & $\gamma$-Decalactone & $2.00 \pm 0.17 \mathrm{c}$ & $57.30 \pm 14.02 \mathrm{a}$ & $19.00 \pm 3.04 \mathrm{~b}$ & $\mathrm{M}, \mathrm{R}, \mathrm{C}$ \\
\hline 1490 & $\operatorname{trans}-\beta$-Ionone & $91.35 \pm 19.70 b$ & $388.19 \pm 69.40 \mathrm{a}$ & $31.49 \pm 16.01 \mathrm{c}$ & $\mathrm{M}, \mathrm{R}, \mathrm{C}$ \\
\hline 1517 & Butylated hydroxytoluene & nd & $0.41 \pm 0.13 \mathrm{a}$ & $0.15 \pm 0.05 b$ & $\mathrm{M}, \mathrm{R}, \mathrm{C}$ \\
\hline 1527 & $\begin{array}{c}44(100), 105(75), 119(72), 91(55), 161(48), \\
\quad 133(40), 77(30), 54(18), 146(15), 177(15)\end{array}$ & nd & $0.09 \pm 0.00 \mathrm{ab}$ & $0.15 \pm 0.10 \mathrm{a}$ & \\
\hline \multirow[t]{6}{*}{1532} & Dihydroactinolide & nd & $0.09 \pm 0.00 \mathrm{a}$ & $0.12 \pm 0.05 \mathrm{a}$ & $\mathrm{M}, \mathrm{R}$ \\
\hline & $\begin{array}{l}\text { Fatty acid-derived and other lipophilic } \\
\text { flavor compounds }\end{array}$ & $7.74 \pm 1.68$ & $49.82 \pm 17.47$ & $18.04 \pm 0.48$ & \\
\hline & Phenylpropanoid/benzenoid compounds & $1.48 \pm 0.09$ & $5.31 \pm 0.68$ & $6.38 \pm 1.36$ & \\
\hline & Terpenoid compounds & $748.98 \pm 120.58$ & $780.65 \pm 28.63$ & $785.41 \pm 41.64$ & \\
\hline & Nitrogen-containing flavor compounds & $0.41 \pm 0.22$ & $0.93 \pm 0.13$ & $2.03 \pm 0.70$ & \\
\hline & Unknown & $0.35 \pm 0.17$ & $1.28 \pm 0.31$ & $0.55 \pm 0.28$ & \\
\hline
\end{tabular}

The three cultivars were 'Houban Yingui' (HBYG), 'Liuye Jingui' (LYJG), and 'Gecheng Dangui' (GCDG). Values, expressed as mean \pm SD of triplicate measurements, with different letters $(\mathrm{a}-\mathrm{c})$ in the same row were significantly different according to Tukey's test $(P<0.05)$. RI: retention index on HP-5 column calculated in the present study. ID: M, comparison of mass spectrum to reference databases; R, comparison of retention index; $\mathrm{C}$, comparison with reference compounds. nd: not detected

Table 2 Aroma-active compounds in flowers of the three sweet osmanthus (Osmanthus fragrans) cultivars

\begin{tabular}{|c|c|c|c|c|c|c|}
\hline \multirow{2}{*}{ RI } & \multirow{2}{*}{ Compound } & \multirow{2}{*}{ Odor descriptor } & \multicolumn{3}{|c|}{ MF (\%) } & \multirow{2}{*}{ ID } \\
\hline & & & HBYG & LYJG & GCDG & \\
\hline 1029 & D-Limonene & Citrus, minty & 8 & 8 & 46 & $\mathrm{M}, \mathrm{R}, \mathrm{O}, \mathrm{C}$ \\
\hline 1047 & cis- $\beta$-Ocimene & Herbal, floral & 71 & 46 & 54 & $\mathrm{M}, \mathrm{R}, \mathrm{O}, \mathrm{C}$ \\
\hline 1051 & trans- $\beta$-Ocimene & Herbal & 96 & 17 & 71 & $\mathrm{M}, \mathrm{R}, \mathrm{O}, \mathrm{C}$ \\
\hline 1061 & $\gamma$-Terpinene & Minty, piney & 65 & nd & 33 & $\mathrm{M}, \mathrm{R}, \mathrm{O}, \mathrm{C}$ \\
\hline 1074 & cis-Linalool oxide & Floral & 71 & 50 & 82 & $\mathrm{M}, \mathrm{R}, \mathrm{O}, \mathrm{C}$ \\
\hline 1091 & trans-Linalool oxide & Floral, green & 71 & 17 & 89 & $\mathrm{M}, \mathrm{R}, \mathrm{O}, \mathrm{C}$ \\
\hline 1103 & Linalool & Floral, lavender & 42 & 84 & 98 & $\mathrm{M}, \mathrm{R}, \mathrm{O}, \mathrm{C}$ \\
\hline 1106 & Hotrienol & Hyacinth & nd & 25 & nd & $\mathrm{M}, \mathrm{R}, \mathrm{O}, \mathrm{C}$ \\
\hline 1110 & $\begin{array}{l}\text { 6-Ethenyldihydro-2,2,6-trimethyl-2H- } \\
\text { pyran-3(4H)-one }\end{array}$ & Orange & 42 & nd & 50 & $\mathrm{M}, \mathrm{R}, \mathrm{O}$ \\
\hline 1133 & Allo-ocimene & Fresh & 74 & 65 & 65 & $\mathrm{M}, \mathrm{R}, \mathrm{O}, \mathrm{C}$ \\
\hline 1145 & Neo-allo-ocimene & Fresh, sweet & 68 & 59 & 65 & $\mathrm{M}, \mathrm{R}, \mathrm{O}$ \\
\hline 1178 & cis-Linalool oxide (pyranoid) & Citrus, green & 65 & 68 & 82 & $\mathrm{M}, \mathrm{R}, \mathrm{O}$ \\
\hline 1191 & cis-3-Hexenyl butanoate & Green, banana & 42 & 84 & 54 & $\mathrm{M}, \mathrm{R}, \mathrm{O}, \mathrm{C}$ \\
\hline 1197 & Hexyl butanoate & Fruity & 33 & 71 & 25 & $\mathrm{M}, \mathrm{R}, \mathrm{O}, \mathrm{C}$ \\
\hline 1354 & 1,2-Dihydro-1,5,8-trimethylnaphthalene & Earthy & nd & 42 & nd & $\mathrm{M}, \mathrm{R}, \mathrm{O}$ \\
\hline 1431 & $\alpha$-Ionone & Woody, violet, fruity & 42 & 59 & 17 & $\mathrm{M}, \mathrm{R}, \mathrm{O}, \mathrm{C}$ \\
\hline 1489 & trans- $\beta$-Ionone & Violet, woody & 50 & 98 & 17 & $\mathrm{M}, \mathrm{R}, \mathrm{O}, \mathrm{C}$ \\
\hline
\end{tabular}

The three cultivars were 'Houban Yingui' (HBYG), 'Liuye Jingui' (LYJG), and 'Gecheng Dangui' (GCDG). RI: retention index on HP-5 column calculated in the present study. MF: modified frequency. ID: M, comparison of the mass spectrum to reference databases; R, comparison of retention index; C, comparison with reference compounds; O, odor described by panelists. nd: not detected 


\subsection{Odor groups}

To analyze the aroma profiles in the three sweet osmanthus cultivars, aroma-active compounds were divided into different groups based on the similarity of their aroma descriptors: violet/woody/fruity, floral, herbal, minty/citrus/orange, green/fresh, and other odors (Table 3). Similar grouping methods have been used for aroma-active compounds in Citrus reticulate (Miyazaki et al., 2012) and Litchi chinensis (Mahattanatawee et al., 2007). The sums of the MF values from GC-O analysis were plotted by groups of aroma descriptors (Fig. 2). The similarity in green/fresh odors among the three cultivars can be explained by the similar total MF values of allo-ocimene, neo-allo-ocimene, and cis-linalool oxide (pyranoid). HBYG presented more herbal odor because its total MF values of $c i s-\beta$-ocimene and trans- $\beta$-ocimene were higher than those in the other two cultivars. LYJG had more violet/woody/fruity odors, especially due to significantly higher MF values of trans- $\beta$ ionone, $\alpha$-ionone, and hexyl butanoate. GCDG had more floral odor because of significantly higher MF values of cis-linalool oxide, trans-linalool oxide, and linalool.

\section{Discussion}

Different aromas have been perceived among three sweet osmanthus cultivar groups with different flower colors by human sensory evaluation (Hu et al., 2012). Most previous reports have concluded that aromas of sweet osmanthus result from major volatiles with high relative contents. However, not all the major volatile compounds contribute to the odor of plants: aroma-active compounds are the key in aroma perception (van Ruth, 2001). To the best of our knowledge, this is the first report investigating aromaactive compounds to explain aroma variation in sweet osmanthus.

As Xin et al. (2013) indicated that aroma characteristics in the same cultivar group had a high degree of similarity, three sweet osmanthus cultivars, HBYG, LYJG, and GCDG, each belonging to a different cultivar group and of major economic importance for flower production in central regions of China (Zhou et al., 2006), were chosen for comparing volatiles and aroma-active compounds in this study.
Table 3 Aroma-active compounds in six groups of aroma descriptors of sweet osmanthus (Osmanthus fragrans)

\begin{tabular}{ll}
\hline \multicolumn{1}{c}{$\begin{array}{c}\text { Descriptor } \\
\text { group }\end{array}$} & \multicolumn{1}{c}{ Compound } \\
\hline $\begin{array}{l}\text { Violet/woody/ } \\
\text { fruity }\end{array}$ & $\alpha$-Ionone, trans- $\beta$-ionone, hexyl butanoate \\
Herbal & cis- $\beta$-Ocimene, trans- $\beta$-ocimene \\
Floral & cis-Linalool oxide, trans-linalool oxide, \\
& linalool \\
Minty/citrus/ & D-Limonene, $\gamma$-terpinene, 6-ethenyldihydro- \\
orange & 2,2,6-trimethyl-2H-pyran-3(4H)-one \\
Green/fresh & cis-Linalool oxide (pyranoid), allo-ocimene, \\
& neo-allo-ocimene, cis-3-hexenyl butanoate \\
Other odors & 1,2-Dihydro-1,5,8-trimethylnaphthalene, \\
& hotrienol \\
\hline
\end{tabular}

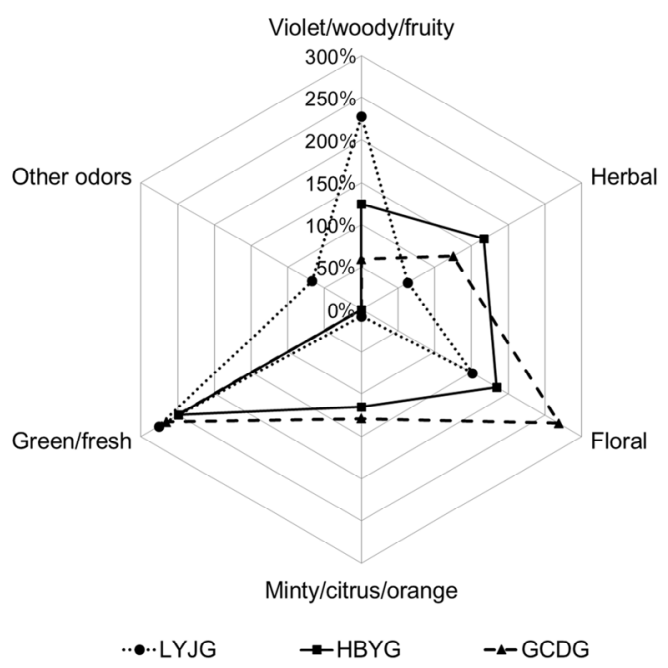

Fig. 2 Aroma profiles of the three sweet osmanthus (Osmanthus fragrans) cultivars 'Liuye Jingui' (LYJG), 'Houban Yingui' (HBYG), and 'Gecheng Dangui' (GCDG) presented by groups of odor-active compounds Data were the sum of MF values (from Table 2) for aromaactive compounds listed in each aroma group category (from Table 3)

The aroma of cultivars from the Albus group has been described as delicate and elegant (Zhu et al., 1985; Hu et al., 2012). Cao et al. (2009) suggested that the high relative content of trans- $\beta$-ocimene produced these aromas. However, other authors have not detected ocimene in this group (Zhu et al., 1985), but linalool and its furanoid oxides, with high relative contents, have been suggested as key aroma compounds (Jin et al., 2006). Based on our GC-O and GC-MS analyses, we confirmed that trans- $\beta$-ocimene, linalool, and trans- $\beta$-ionone are the important aromaactive compounds in HBYG. Furthermore, some compounds with low contents, such as 6-ethenyldihydro2,2,6-trimethyl-2H-pyran-3(4H)-one $(2.20$ relative 
units), $\gamma$-terpinene (1.60 relative units), and cis-3hexenyl butanoate ( 0.99 relative units), also contributed to the aroma of HBYG. Considering our odor group results, the delicate and elegant aroma characteristics of the Albus group may be the result of the prominent herbal odors of trans- $\beta$-ocimene and cis- $\beta$-ocimene. These aroma-active compounds have generally been associated with the presence of herbal and grassy odors in leaves and stems of plants such as Schizandra chinensis (Zheng et al., 2005) and $C$. coronarium (Zheng et al., 2004).

The aroma of cultivars from the Luteus group has been reported as strong and sweet (Zhu et al., 1985; Hu et al., 2012). In previous aroma studies of the Luteus group, $\alpha$-ionone, $\beta$-ionone, and $\gamma$-decalactone have been considered as major volatiles contributing to the strong sweet scent (Zhu et al., 1985; Li et al., 2008; Cao et al., 2009). In this work, $\alpha$-ionone and trans- $\beta$-ionone, with high contents, were detected as aroma-active compounds, whereas, despite its high content, $\gamma$-decalactone in LYJG was not perceived as an aroma-active compound in GC-O analysis. Although the content of hexyl butanoate was low in LYJG (1.22 relative units), it was identified as one of the odorants with the greatest impact. The total MF values of trans- $\beta$-ionone, $\alpha$-ionone, and hexyl butanoate in LYJG were much higher than those in the other two cultivars, and characterized by violet/ woody/fruity odors. The odors of these compounds have been reported in many fruits, such as Rubus fruticosus (Du et al., 2010), Rubus idaeus (Klesk et al., 2004), and C. reticulate (Miyazaki et al., 2012), indicating that the strong sweet aroma impression of the Luteus group might be caused by these odors.

The aroma of cultivars from the Aurantiacus group has been deemed to be less elegant than that of the Albus group and less sweet than that of the Luteus group by olfactory sensation (Zhu et al., 1985; Hu et al., 2012). Previous studies have stated that the aroma of the Aurantiacus group was less sweet than that of the Luteus group because of the lack of ionone (Zhu et al., 1985; Cao et al., 2009), and that the level of delicate elegance was lower than that in the Albus group due to the lack of ocimene (Cao et al., 2009). However, our GC-MS results showed that trans- $\beta$ ocimene and trans- $\beta$-ionone are major volatiles of GCDG. The herbal odors detected and the total MF values of trans- $\beta$-ocimene and cis- $\beta$-ocimene in GCDG were lower than those in HBYG, although trans- $\beta$-ocimene was a herbal odorant with a high $\mathrm{MF}$ value $(71 \%)$ in GCDG. Violet/woody/fruity odors were lower in GCDG than in LYJG because the total MF values of trans- $\beta$-ionone, $\alpha$-ionone, and hexyl butanoate were low. Considering that the characteristic plant aroma should arise from a mixture of several aroma-active compounds (Liu et al., 2012), the less elegant and sweet aroma impression of GCDG might be due to the total MF values of aroma-active compounds which contributed to herbal and violet/ woody/fruity odors. Linalool and its oxides had not only high content, but also high MF values in GCDG. Giving a typical floral odor in sweet osmanthus, they have also been reported as giving floral odor in flowers of species such as L. nobilis (Kilic et al., 2004) and Wisteria brachybotrys (Miyazawa et al., 2011). However, this floral aroma impression has not been considered in previous research on sweet osmanthus.

Color and aroma are two major characters of flowers, and they may be linked by shared biosynthetic pathways (Delle-Vedove et al., 2011). As the aroma varied among different cultivars with white, yellow, and orange flower colors, there may be coloraroma associations in sweet osmanthus. $\alpha$-Ionone and trans- $\beta$-ionone, which were the main aroma-active compounds in present study, have been reported as carotenoid cleavage derivatives of $\alpha$-carotene and $\beta$-carotene in sweet osmanthus (Baldermann et al., 2010; 2012). Han et al. (2014) have indicated that $\alpha$-carotene and $\beta$-carotene are abundant in a cultivar of the Aurantiacus group, but nearly non-existent in cultivars of the Albus and Luteus groups. Here we found that the contents and aroma intensities of $\alpha$-ionone and trans- $\beta$-ionone in cultivars of the Albus and Luteus groups were much higher than those in the Aurantiacus group (Tables 1 and 2). This potential association might be due to a faster cleavage rate of carotenoids in cultivars in the Albus and Luteus groups compared to the Aurantiacus group (Han et al., 2013). Linalool and trans- $\beta$-ocimene were also important aroma-active compounds in sweet osmanthus (Table 2). They are terpenoids, formed directly from geranyl diphosphate (GPP) via the isoprenoid pathway shared by carotenoids (Lewinsohn et al., 2001). 
Considering that most of the aroma-active compounds in sweet osmanthus are terpenoids, the coloraroma associations between carotenoids and terpenoids appear to have a major influence on the aroma impressions among different cultivar groups. Further research is needed on the color-aroma associations of sweet osmanthus.

\section{Conclusions}

The difference in aroma among sweet osmanthus cultivars was analyzed using odor descriptions and intensities of aroma-active compounds. The delicate and elegant aroma impression of the creamy-white flower cultivar HBYG was due to $c i s-\beta$-ocimene and trans- $\beta$-ocimene, with high intensities of herbal odors. The yellow flower cultivar LYJG had a strong sweet aroma perception resulting from trans- $\beta$-ionone, $\alpha$-ionone, and hexyl butanoate, which have higher violet/woody/fruity odors. The orange flower cultivar GCDG had more floral odor, imparted by cis-linalool oxide, trans-linalool oxide, and linalool. A comparison of GC-O with the semi-quantitative GC-MS results showed that aroma-active compounds are not necessarily the most abundant volatiles, and some volatiles with low content also contributed to aroma. GC-O analysis could contribute to more precise knowledge of the contribution of volatiles to aroma. Considering that most aroma-active compounds are terpenoids, the color-aroma associations between carotenoids and terpenoids appear to influence the aroma impressions. This study provides useful information on the aroma characteristics of sweet osmanthus for future commercial applications and breeding efforts, and will be helpful for further research on the relationship between color and aroma in sweet osmanthus.

\section{Acknowledgements}

The authors thank Gang FAN, Gui-yan AO, Jun ZHANG, and Xiao-huan LIAO from the College of Food Science and Technology, Huazhong Agricultural University (Wuhan, China) for their technical assistance in this research.

\section{Compliance with ethics guidelines}

Xuan CAI, Rong-zhang MAI, Jing-jing ZOU, Hong-yan ZHANG, Xiang-ling ZENG, Ri-ru ZHENG, and Cai-yun
WANG declare that they have no conflict of interest.

This article does not contain any studies with human or animal subjects performed by any of the authors.

\section{References}

Baldermann, S., Kato, M., Kurosawa, M., et al., 2010. Functional characterization of a carotenoid cleavage dioxygenase 1 and its relation to the carotenoid accumulation and volatile emission during the floral development of Osmanthus fragrans Lour. J. Exp. Bot., 61(11):29672977. [doi:10.1093/jxb/erq123]

Baldermann, S., Kato, M., Fleischmann, P., et al., 2012. Biosynthesis of $\alpha$ - and $\beta$-ionone, prominent scent compounds, in flowers of Osmanthus fragrans. Acta Biochim. Pol., 59(1):79-81.

Buchbauer, G., Jirovetz, L., Jager, W., et al., 1993. Fragrance compounds and essential oils with sedative effects upon inhalation. J. Pharm. Sci., 82(6):660-664. [doi:10.1002/ jps.2600820623]

Cao, H., Li, Z.G., Shen, D.L., 2009. GC/MS fingerprint analysis of Osmanthus fragrans Lour. in different varieties. Acta Hort. Sin., 36(3):391-398 (in Chinese).

Culleré, L., San-Juan, F., Cacho, J., 2011. Characterisation of aroma active compounds of Spanish saffron by gas chromatography-olfactometry: quantitative evaluation of the most relevant aromatic compounds. Food Chem., 127(4):1866-1871. [doi:10.1016/j.foodchem.2011.02.015]

Delle-Vedove, R., Juillet, N., Bessiere, J.M., et al., 2011. Colour-scent associations in a tropical orchid: three colours but two odours. Phytochemistry, 72(8):735-742. [doi:10.1016/j.phytochem.2011.02.005]

Dravnieks, A., 1985. Atlas of Odor Character Profiles. ASTM, Philadelphia, p.354.

Du, X.F., Finn, C.E., Qian, M.C., 2010. Volatile composition and odour-activity value of thornless 'Black Diamond' and 'Marion' blackberries. Food Chem., 119(3):11271134. [doi:10.1016/j.foodchem.2009.08.024]

Han, Y.J., Li, L.X., Dong, M.F., et al., 2013. cDNA cloning of the phytoene synthase $(P S Y)$ and expression analysis of $P S Y$ and carotenoid cleavage dioxygenase genes in $O s$ manthus fragrans. Biologia, 68(2):258-263. [doi:10. 2478/s11756-013-0002-z]

Han, Y.J., Wang, X.H., Chen, W.C., et al., 2014. Differential expression of carotenoid-related genes determines diversified carotenoid coloration in flower petal of Osmanthus fragrans. Tree Genet. Genomes, 10(2):329-338. [doi:10. 1007/s11295-013-0687-8]

Hu, B.F., Guo, X.L., Xiao, P., et al., 2012. Chemical composition comparison of the essential oil from four groups of Osmanthus fragrans Lour. flowers. J. Essent. Oil Bear. Plants, 15(5):832-838. [doi:10.1080/0972060X.2012.106 44128]

Hung, C.Y., Tsai, Y.C., Li, K.Y., 2012. Phenolic antioxidants 
isolated from the flowers of Osmanthus fragrans. Molecules, 17(12):10724-10737. [doi:10.3390/molecules 1709 10724]

Jin, H.X., Zheng, H., Jin, Y.J., et al., 2006. Research on major volatile components of 4 Osmanthus fragrance cultivars in Hangzhou Manlong Guiyu park. Forest. Res., 19(5): 612-661 (in Chinese).

Kang, W., Li, Y., Xu, Y., et al., 2012. Characterization of aroma compounds in Chinese bayberry (Myrica rubra Sieb. et Zucc.) by gas chromatography mass spectrometry (GC-MS) and olfactometry (GC-O). J. Food Sci., 77(10): C1030-C1035. [doi:10.1111/j.1750-3841.2012.02747.x]

Kaseleht, K., Leitner, E., Paalme, T., 2011. Determining aroma-active compounds in kama flour using SPMEGC/MS and GC-olfactometry. Flavour Frag. J., 26(2): 122-128. [doi:10.1002/ffj.2032]

Kilic, A., Hafizoglu, H., Kollmannsberger, H., et al., 2004. Volatile constituents and key odorants in leaves, buds, flowers, and fruits of Laurus nobilis L. J. Agric. Food Chem., 52(6):1601-1606. [doi:10.1021/jf0306237]

Klesk, K., Qian, M., Martin, R.R., 2004. Aroma extract dilution analysis of cv. Meeker (Rubus idaeus L.) red raspberries from Oregon and Washington. J. Agric. Food Chem., 52(16):5155-5161. [doi:10.1021/jf0498721]

Knudsen, J.T., Eriksson, R., Gershenzon, J., et al., 2006. Diversity and distribution of floral scent. Bot. Rev., 72(1): 1-120. [doi:10.1663/0006-8101(2006)72[1:DADOFS]2.0. $\mathrm{CO} ; 2]$

Lee, D.G., Lee, S.M., Bang, M.H., et al., 2011. Lignans from the flowers of Osmanthus fragrans var. aurantiacus and their inhibition effect on NO production. Arch. Pharm. Res., 34(12):2029-2035. [doi:10.1007/s12272-011-1204-y]

Lewinsohn, E., Schalechet, F., Wilkinson, J., et al., 2001. Enhanced levels of the aroma and flavor compound $S$-linalool by metabolic engineering of the terpenoid pathway in tomato fruits. Plant Physiol., 127(3): 1256-1265. [doi:10.1104/pp.010293]

Li, Z.G., Cao, H., Zhu, G.H., et al., 2008. Study on chemical constituents of fragrance released from fresh flowers of three different Osmanthus franrans Lour. during different florescences. Chem. Ind. For. Prod., 28(3):75-80 (in Chinese).

Liu, C.H., Cheng, Y.J., Zhang, H.Y., et al., 2012. Volatile constituents of wild citrus Mangshanyegan (Citrus nobilis Lauriro) peel oil. J. Agric. Food Chem., 60(10):26172628. [doi:10.1021/jf2039197]

Mahattanatawee, K., Perez-Cacho, P.R., Davenport, T., et al., 2007. Comparison of three lychee cultivar odor profiles using gas chromatography-olfactometry and gas chromatography-sulfur detection. J. Agric. Food Chem., 55(5):1939-1944. [doi:10.1021/jf062925p]

Miyazaki, T., Plotto, A., Baldwin, E.A., et al., 2012. Aroma characterization of tangerine hybrids by gas- chromatography-olfactometry and sensory evaluation. $J$. Sci. Food Agric., 92(4):727-735. [doi:10.1002/jsfa.4663]

Miyazawa, M., Marumoto, S., Kobayashi, T., et al., 2011. Determination of characteristic components in essential oils from Wisteria brachybotrys using gas chromatographyolfactometry incremental dilution technique. Rec. Nat. Prod., 5(3):221-227.

Montero-Calderón, M., Rojas-Graü, M.A., Martin-Belloso, O., 2010. Aroma profile and volatiles odor activity along gold cultivar pineapple flesh. J. Food Sci., 75(9):S506S512. [doi:10.1111/j.1750-3841.2010.01831.x]

Sides, A., Robards, K., Helliwell, S., 2000. Developments in extraction techniques and their application to analysis of volatiles in foods. TrAC Trend Anal. Chem., 19(5): 322-329. [doi:10.1016/S0165-9936(99)00225-3]

Tsai, P.J., Tsai, T.H., Yu, C.H., et al., 2007. Comparison of $\mathrm{NO}$-scavenging and NO-suppressing activities of different herbal teas with those of green tea. Food Chem., 103(1):181-187. [doi:10.1016/j.foodchem.2006.08.013]

Ubeda, C., Callejon, R.M., Troncoso, A.M., et al., 2012. Characterization of odour active compounds in strawberry vinegars. Flavour Frag. J., 27(4):313-321. [doi:10. $1002 /$ ffj.3103]

van Ruth, S.M., 2001. Methods for gas chromatographyolfactometry: a review. Biomol. Eng., 17(4-5):121-128. [doi:10.1016/S1389-0344(01)00070-3]

Wang, L.M., Li, M.T., Jin, W.W., et al., 2009. Variations in the components of Osmanthus fragrans Lour. essential oil at different stages of flowering. Food Chem., 114(1): 233-236. [doi:10.1016/j.foodchem.2008.09.044]

Wu, L.C., Chang, L.H., Chen, S.H., et al., 2009. Antioxidant activity and melanogenesis inhibitory effect of the acetonic extract of Osmanthus fragrans: a potential natural and functional food flavor additive. LWT-Food Sci. Technol., 42(9):1513-1519. [doi:10.1016/j.lwt.2009.04.004]

Xin, H.P., Wu, B.H., Zhang, H.H., et al., 2013. Characterization of volatile compounds in flowers from four groups of sweet osmanthus (Osmanthus fragrans) cultivars. Can. J. Plant Sci., 93(5):923-931. [doi:10.4141/cjps2012-333]

Yuan, W.J., Han, Y.J., Dong, M.F., et al., 2011. Assessment of genetic diversity and relationships among Osmanthus fragrans cultivars using AFLP markers. Electron. J. Biotechnol., 14(1):1-9. [doi:10.2225/vol14-issue1-fulltext-9]

Zang, D.K., Xiang, Q.B., Liu, Y.L., et al., 2003. The studying history and the application to International Cultivar Registration Authority of sweet osmanthus (Osmanthus fragrans Lour.). J. Plant Resour. Environ., 12(4):49-53 (in Chinese).

Zheng, C.H., Kim, T.H., Kim, K.H., et al., 2004. Characterization of potent aroma compounds in Chrysanthemum coronarium L. (Garland) using aroma extract dilution analysis. Flavour Frag. J., 19(5):401-405. [doi:10.1002/ ffj.1447] 
Zheng, C.H., Kim, K.H., Kim, T.H., et al., 2005. Analysis and characterization of aroma-active compounds of Schizandra chinensis (omija) leaves. J. Sci. Food Agric., 85(1): 161-166. [doi:10.1002/jsfa.1975]

Zhou, Y., Yao, C.H., Wang, C.Y., 2006. Study on selecting cut-flower cultivars of Osmanthus fragrans. J. Zhejiang Forest Coll., 23(6):660-663 (in Chinese).

Zhu, M.L., Ding, D.S., Huang, Z.X., et al., 1985. Head space constituents of different varieties of Osmanthus fragrans. Acta Hort. Sin., 27(4):412-418 (in Chinese).

\section{中文㩯要：}

本文题目: 运用气相色谱-嗅觉测量法和气质联用法分析三个桂花品种的香气活性物质

Analysis of aroma-active compounds in three sweet osmanthus (Osmanthus fragrans) cultivars by GC-olfactometry and GC-MS

研究目的：分析不同桂花品种感官评价差异所对应的香气成分, 及其有贡献的香气活性物质, 为桂花的 生物科学应用提供依据。

创新要点: 首次运用气相色谱-嗅觉测量法 (GC-O) 结合气质联用法 (GC-MS) 对所分离的挥发性物质 进行定性和半定量分析，并同时结合其气味描述，分析不同桂花品种的香气活性物质特征。 本研究还根据所检测的香气活性物质的气味特征对香气活性物质进行分组, 能更直观地分析 桂花不同品种香气差异的原因。

研究方法:（1）运用 GC-MS 对三个桂花品种的挥发性物质进行定性和半定量的比较分析（见表 1）; （2）运用 GC-O 对三个桂花品种香气活性物质进行比较分析（见表 2）；（3）对香气活性 物质进行分组，探究不同桂花品种的香气差异原因（见表 3 和图 2）。

重要结论: (1) GC-O 结合 GC-MS 分析所得香气活性物质并非都是含量较高的挥发性物质, 有些含量 较低的挥发性物质也对桂花香气形成有贡献; (2) 不同桂花品种的香气差异是由不同香气分 组以及香气活性物质强度不同所致。

关键词组: 桂花; 香气; 气相色谱-嗅觉测量法; 气质联用法 